Uma análise contextual do funcionamento efetivo e participação popular em uma unidade de conservação: o caso da área de proteção ambiental de Petrópolis (Rio de Janeiro: Brasil)

Marco Pinheiro Gonçalves, Fátima Teresa Braga Branquinho, Israel Felzenszwalb

\title{
UMA ANÁLISE CONTEXTUAL DO FUNCIONAMENTO EFETIVO E PARTICIPAÇÃO POPULAR EM UMA UNIDADE DE CONSERVAÇÃO: O CASO DA ÁREA DE PROTEÇÃO AMBIENTAL DE PETRÓPOLIS (RIO DE JANEIRO: BRASIL)
}

\section{A contextual analysis of the effective functioning and popular participation in a Conservation Unit: the case of Environmental Protection Area of Petrópolis (Rio de Janeiro: Brazil)}

Marco Pinheiro Gonçalves

Bolsista FAPERJ - Doutorando do PPG - Meio Ambiente, UERJ

Rio de Janeiro/RJ - Brasil

marcopgoncalves@hotmail.com

Fátima Teresa Braga Branquinho

Prof $^{a}$. Adjunta da Faculdade de Educação e PPG - Meio Ambiente, UERJ

Rio de Janeiro/RJ - Brasil

fatima.branquinho@uol.com.br

Israel Felzenszwalb

Prof $^{\circ}$. Associado do Depto. De Biofísica e Biometria, Instituto de Biologia, UERJ

Rio de Janeiro/RJ - Brasil

uerj.felzen@gmail.com

Artigo recebido para publicação em 08/10/2010 e aceito para publicação em 20/04/2011

RESUMO: Unidades de conservação da natureza sofrem historicamente de problemas envolvendo, por exemplo, administração pública e legitimação popular, o que reflete quadros de ineficiência e conflitos locais em vários níveis. Nesse contexto, a Área de Proteção Ambiental de Petrópolis é abordada no presente trabalho, com o objetivo de se traçar um panorama sistêmico de tal proposta de sustentabilidade, observando a história local, a gestão pública e a participação popular. É proposta, portanto, uma análise da paisagem local de maneira sistêmica e integrada, sob um referencial teórico que engloba: políticas locais, manejo de unidades de conservação, conflitos ambientais e participação social. Como resultados, pode-se destacar um quadro de gestão pública de baixa eficiência e conflitos de interesse e gestão. $O$ caráter unilateral das tomadas de decisão e confecção do zoneamento ambiental, aliadas ao contexto de ineficiência histórica da gestão dos órgãos públicos competentes foram identificados como entraves ao bom funcionamento da unidade. Criada em 1982, a proposta da APA se apresenta ainda hoje aberta e inovadora; porém, tal inovação no modelo de unidades de conservação esbarra na gestão pública de baixa eficiência e na visão preservacionista dominante nas esferas técnicas. Destaca-se, ainda: o conflito entre as diferentes esferas do poder público, e os conflitos entre os poderes locais e os interesses em conservação da natureza como fenômenos que dificultam a consecução de propostas práticas de conservação. Defende-se que a observação da diversidade dos atores existentes na paisagem da APA e a participação social efetiva sejam caminhos para se atingir os objetivos de sustentabilidade, e o uso do conceito de redes sociotécnicas será de grande valia para as novas abordagens que se propõem. O segmento universitário é indicado como provedor de importantes elos sociotécnicos que servirão como alavancas à participação social solidária, e assim ao conhecimento e aproximação aos atores e problemas locais. 
Uma análise contextual do funcionamento efetivo e participação popular em uma unidade de conservação: o caso da área de proteção ambiental de Petrópolis (Rio de Janeiro: Brasil)

Marco Pinheiro Gonçalves, Fátima Teresa Braga Branquinho, Israel Felzenszwalb

Palavras-chaves: Área de Proteção Ambiental. Gestão ambiental. Unidades de conservação. Paisagem. Redes sociotécnicas

ABSTRACT: Nature conservation units have historically suffered with problems involving, for example, public administration and popular legitimacy, which reflect in inefficiency boards and local conflicts at various levels. On this context, the Environmental Protection Area of Petrópolis (APA Petrópolis) is investigated on this contribution, following the intention to give a systemic overview of this sustainability proposal, observing the local history, public management and popular participation. We propose, indeed, an systemic and integrated analisys of the local landscape, involving studies in local: politics, conservation units management, environmental conflicts. As results, we describe low eficiency public administration anda conflicts of interest and management. The unilateral character of decision making and the environmental zoning, combined with the historical context of inefficient management of responsible public agencies were identified as obstacles to the well functioning of the unit. Created in 1982, the APA proposal is still presented as open and innovative; nevertheless, the innovation suggested by this model collides to the low efficiency of public administration and the preservationist vision, dominant at the technical spheres. It is noteworthy, in addiction: the conflict between the different governmental spheres, as well the conflicts between local interests and the nature conservation act as phenomena that complicate the achievement of proposed conservation practices. We defend that the observation on the diversity of actors playing a role in the APA landscape, and the effective social participation are ways to achieve sustainability goals, and the use of the concept of sociotechnical nets would be valuable to the new views proposed. The university segment is indicated as a provider of important socio-technical links that will serve as levers for social participation, and thus to the knowledge and approach to local actors and local problems.

Keywords: Environmental Protection Areas. Environmental Management. Conservation units. Landscape. Socio-technical nets.

\section{INTRODUÇÃO}

Áreas de Proteção Ambiental (APAs; unidades de conservação de uso sustentável, segundo a categorização do Sistema Nacional de Unidades de Conservação, SNUC; BRASIL, 2000) são consideradas pertinentes alternativas ao tradicional formato funcional de unidades de conservação, devido à renovação que trazem aos modelos preservacionistas restritivos dominantes do século passado (como Reservas Biológicas e Parques Nacionais, por exemplo). Tais Unidades de Conservação (UCs) tradicionais enfrentam dificuldades de implantação e funcionamento, apontadas em diversas contribuições devido a diversas situações socioambientais no Brasil e no mundo (ARRUDA, 1999; COLCHESTER, 2000; GUHA, 2000; SCHWARTZMAN, 2000; DIEGUES, 2000; 2004; entre outros). Uma coleção de culturas distintas, usos tradicionais da terra e ecossistemas com diferentes características produtivas conferem ao Brasil a posição de país dotado de muitas situações de conflitos ambientais, e as UCs criadas no modelo tradicional fazem parte desse quadro, por vezes agravando as situações de conflitos ou gerando novos (ARRUDA, 1999).

A concepção original de áreas protegidas no Brasil e em boa parte das nações em desenvolvimento é derivada do modelo norte-americano do século passado, que visava proteger a vida selvagem ameaçada pela civilização urbano-industrial crescente (excelentes históricos sobre a gênese e evolução do conceito de unidades de conservação da natureza podem ser encontrados, por exemplo, em DIEGUES, 2000; 2004; e ARAÚJO, 2007). Esse modelo se expandiu mundialmente principalmente a partir da década de 1960, quando houve aumento exponencial do número 
Uma análise contextual do funcionamento efetivo e participação popular em uma unidade de conservação: o caso da área de proteção ambiental de Petrópolis (Rio de Janeiro: Brasil)

Marco Pinheiro Gonçalves, Fátima Teresa Braga Branquinho, Israel Felzenszwalb

de áreas protegidas em todo o mundo (ARRUDA, 1999; ARAÚJO, 2007). A idéia defendida nesse tipo de modelo é a de que a domesticação e descaracterização da natureza seriam inevitáveis, o que torna necessária a conservação de partes intactas da vida selvagem em seu estado "original" e longe do contato humano, reservada apenas para reverência e pesquisa. Tais reservas seriam idealizadas segundo preceitos científicos que recrudesciam em meados do século passado, notadamente a biologia da conservação, biogeografia e ecologia. Essas unidades seriam então geridas pelo poder público, sujeitas a um regime de proteção externo, à observação técnica-científica (muitas das vezes por pesquisadores estrangeiros) e à legislação proposta.

Uma abertura a esse modelo tradicional pode ser exemplificada pelas Áreas de Proteção Ambiental - APAs - modelos de UC menos restritivos e tipicamente nacionais. Nestas, seriam possíveis distintos usos da terra aliados à preservação ambiental, esforços que serviriam às intenções de conservação de modo prático: a situação fundiária da unidade seria menos relevante, assim como seriam defendidas práticas sustentáveis, e a legislação poderia ser cumprida por esforços políticos direcionados. As APAs começaram a ser criadas em 1982, simbolizando um novo paradigma na conservação de recursos naturais no Brasil (ARAÚJO, 2007), e serviriam para congregar aspectos ambientais e sociais em uma mesma paisagem protegida. Hoje, as APAs são criadas nas esferas municipal, estadual e federal, sendo o principal instrumento da categoria de Unidades de Conservação de Uso Sustentável do SNUC. Somente as APAs federais somavam 7.947.916,26 hectares sob tal regime de proteção em 2003 (IBAMA-WWF, 2007). A despeito das dificuldades surgidas no modelo tradicional, e das possibilidades da aplicação de uma proposta menos restritiva, a implementação de uma APA encontra diversos desafios.

Vários exemplos do funcionamento de APAs são encontrados na literatura, relatando êxitos distintos e apontando problemas e dificuldades (MORAES, 2004; TEIXEIRA, 2005; COZZOLINO; IRVING, 2007, por exemplo); em todos os casos, o processo de implantação e funcionamento envolve uma série de aspectos políticos e socioambientais que advém de contextos históricos específicos, aliados às políticas ambientais que serviram como pano de fundo. De maneira geral, o conceito de desenvolvimento sustentável, popular a partir da década de 1980, é o paradigma que norteia a criação de tais unidades. Porém, suas implantações ainda foram realizadas, pelo menos inicialmente, sob a ótica preservacionista reinante nos órgãos gestores e comissões técnicas incumbidas de produzir os documentos técnicos legais imprescindíveis para a instalação e funcionamento das unidades (TEIXEIRA, 2005). A inserção das questões populares e a participação das comunidades afetadas, nesses casos, passam a ser fatores determinantes na efetividade de tais propostas (MORAES, 2004), principalmente se vistas sob a ótica dos novos paradigmas ecológicos e de uma ecologia política, onde aspectos das sociedades humanas e suas relações (culturais e econômicas) passam a ser determinantes para qualquer iniciativa de sustentabilidade (LITTLE, 2006).

A presente contribuição usa como exemplo a Área de Proteção Ambiental de Petrópolis (APA Petrópolis, região serrana do Rio de Janeiro, Figura 1), a primeira APA criada no Brasil - e uma das mais relevantes Unidades de Conservação de uso sustentável da Mata Atlântica. Visa discutir a proposta de gestão e manejo da paisagem (conceito segundo Santos, 1994; SILVA, 1997; HOLZER, 1999), delimitada sobre a APA Petrópolis. Tal análise se dá em três momentos distintos: primeiramente sob a ótica de sua história recente e sua implantação; em seguida, analisando os efeitos dos governos locais sobre a proposta da APA; por fim, abordando as questões relacionadas à compreensão dos relacionamentos sóciotécnicos como indispensáveis aos esforços de conservação. 
Uma análise contextual do funcionamento efetivo e participação popular em uma unidade de conservação: o caso da área de proteção ambiental de Petrópolis (Rio de Janeiro: Brasil)

Marco Pinheiro Gonçalves, Fátima Teresa Braga Branquinho, Israel Felzenszwalb

Figura 1: Mapa de localização da APA Petrópolis. Modificado de GRAEFF, 2003.

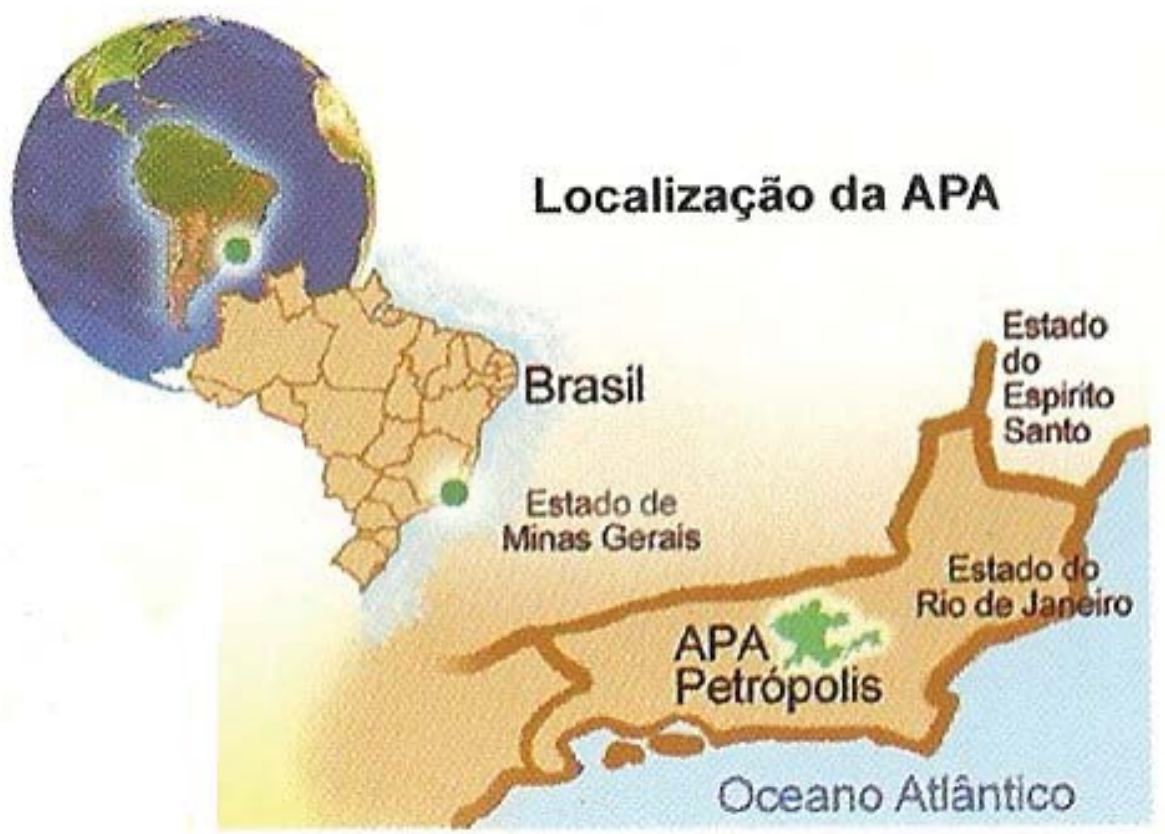

O CONTEXTO DO SURGIMENTO DA APA PETRÓPOLIS, NA IMPLANTAÇÃO E LEGITIMAÇÃO POPULAR DA UC

A APA Petrópolis é uma Unidade de Conservação que engloba quase todo o município de Petrópolis, toda sua área urbana e os limites com outros municípios (SEMADS, 2001; GRAEFF, 2003). Sua criação data de 1982, sendo o marco inicial das UCs de uso sustentável, pela proposta de englobar núcleos urbanos, importantes parcelas de florestas e nascentes de relevantes corpos hídricos, se avizinhar com outras UCs e também conter relevante acervo histórico. Porém, diversos fatores têm contribuído para que essa proposta não se solidifique; a APA Petrópolis como instituição, em 28 anos de existência, não ofereceu soluções para muitos dos conflitos hodiernos e históricos regionais, como ocupações irregulares de áreas de risco, atividades poluidoras, degradação dos corpos d'água e supressão das florestas remanescentes. Em suma, o quadro socioambiental da APA Petrópolis não difere substancialmente daqueles constantes em cidades médias sem qualquer caráter de proteção do poder público. Tal quadro de ineficiência se construiria sob qual contexto?
Petrópolis possui um acervo histórico relacionado com o Brasil Império, além de abundâncias naturais e um clima ameno que marcou sua história e seus usos como cidade de veraneio. Sua construção notadamente contou com a contribuição de imigrantes alemães, sendo seu curioso e moderno planejamento datado de meados do século XIX. Conhecido como Plano Köeler (nome do Major alemão que planejou Petrópolis), esse planejamento fora encomendado por D. Pedro II para que tal cidade se tornasse não uma vila, mas um dos centros do Império. Previa, entre outras características, tamanhos mínimos de lotes de terras e construções distantes dos corpos d'água, e a preservação de mananciais e encostas. O Plano Köeler sobreviveu em sua proposta visionária até meados do século XX, época em que o país - e particularmente o Rio de Janeiro - viu surgir um grande crescimento industrial e demográfico. A principal estrada para o interior - BR-040, que corta a cidade, teve seu trânsito aumentado com a construção de Brasília, o que iluminou ainda mais a região para o crescimento. Tal processo desfigurou em parte a proposta inicial de zoneamento, fazendo surgir um contexto urbano novo em Petrópolis. O aparato histórico, com suas características bucólicas, as encostas verdes e o 
Uma análise contextual do funcionamento efetivo e participação popular em uma unidade de conservação: o caso da área de proteção ambiental de Petrópolis (Rio de Janeiro: Brasil)

Marco Pinheiro Gonçalves, Fátima Teresa Braga Branquinho, Israel Felzenszwalb

sossego dos bairros residenciais estavam ameaçados pelo crescimento urbano desenfreado. A ocupação industrial desordenada e poluição passaram a fazer parte da paisagem. Nesse contexto, surge a proposta inicial da APA Petrópolis (precisamente em 1982: Art. $6^{\circ}$ do Decreto Federal $n^{\circ} 87.561$ ). Os alvos da conservação eram claramente o centro histórico e os mananciais que abastecem até hoje a cidade, frente a conflitos, mudanças nos usos da terra e favelização que floresciam a essa época em todo o estado do Rio de Janeiro (ACSELRAD, 2004).

AAPA Petrópolis foi então criada, inaugurando-se no Brasil uma nova modalidade de Unidade de Conservação. Assim, tal proposta viria de encontro à ameaça crescente ao conjunto arquitetônico secular (de caráter eminentemente privado na região, com os casarões e palacetes de jardins suntuosos), e se caracteriza como uma decisão de grupos sociais restritos, tornando a proposta distante da legitimação popular.

A delimitação da APA Petrópolis, no entanto, seria realizada apenas em 1992, e a implantação física da APA, apenas em 1997, com a formação de um conselho gestor (GRAEFF, 2003). Nesse intervalo, onde não havia manifestação institucional para a gestão da APA, houve um agravamento das condições ambientais locais, principalmente em relação às ocupações de encostas e desmatamentos (BAPTISTA et al. 2005; BAPTISTA; CALIJURI, 2007), mas também em relação à degradação de corpos hídricos e solos (OLIVEIRA, 2006). Mesmo após a implantação de uma sede física, a inatividade histórica do órgão gestor (à época, o IBAMA) não impediu a continuidade da ocupação desordenada, os crimes ambientais e o sucessivo desmando dos governos locais.

De fato, a APA Petrópolis possui hoje um Conselho Deliberativo, existente e atuante (GRAEFF, 2003; COZZOLINO; IRVING, 2007), apesar das interrupções constantes derivadas das mudanças políticas nas instituições envolvidas. Do universo de Unidades de Conservação de uso Sustentável (APAs e Áreas de Relevante Interesse Ecológico, ÁRIEs), poucas já têm os instrumentos básicos de gestão previstos pela legislação (Lei no 9.985 de 18 de julho de 2000, que institui o Sistema Nacional das Unidades de Conservação, conhecido como SNUC): Plano de manejo, zoneamento e conselho gestor. De uma maneira geral, a efetividade de gestão dessa categoria de Unidade de Conservação (APAs e ÁRIEs) é criticamente baixa, apresentando alta vulnerabilidade ambiental, e baixa capacidade de planejamento e organização (IBAMA-WWF, 2007). Segundo esse mesmo relatório, versando sobre a efetividade de gestão das UCs de uso sustentável Federais:

\section{[...] A maioria dos resultados obtidos não al-} cança desempenho satisfatório, excetuando-se ações de divulgação, prevenção de ameaças e relações com as comunidades locais, com valores médios na análise em questão. Todos os demais temas são críticos[...] (IBAMA WWF, 2007 p. 52).

\section{O contexto cultural da administração pública} brasileira (termo explorado por ARAÚJO; PINTO-COELHO, 2007) explica os baixos desempenhos apresentados pelas UCs (bons exemplos em ARAÚJO, 2007), onde a administração, sofrendo influência dos sistemas superiores burocratizados, chega a um panorama de ineficiência generalizada, como atribuem os autores supracitados. As UCs seriam, portanto, o espelho da administração pública, com características típicas como lentidão, personalismo, formalismo, centralização do poder e outras deficiências. Uma carga mínima de funcionários, recursos limitados e falta de projeções técnicas e operacionais são exemplos que alinham o caso da APA Petrópolis, nosso objeto de estudo, com as afirmações dos autores supracitados.

A gestão de Unidades de Conservação demanda participação social, sobretudo aquelas onde os contingentes humanos são afetados diretamente. Regimes de controle e regulação externos tendem ao fracasso, causando por vezes o inverso das intenções de conservação, fazendo crescer as pressões sobre as florestas nativas não protegidas e causando distorções na percepção local (ARRUDA, 1999); outrossim, os instrumentos legais de participação popular já são legalmente consagrados: o Plano de manejo e conselho gestor - abertos ao comparecimento das parcelas da população envolvida - e são imprescindíveis para a consecução dos projetos visando o bem social. Essa participação pode ser considerada um dos grandes desafios práticos, pois raramente se dá de forma igua- 
Uma análise contextual do funcionamento efetivo e participação popular em uma unidade de conservação: o caso da área de proteção ambiental de Petrópolis (Rio de Janeiro: Brasil)

Marco Pinheiro Gonçalves, Fátima Teresa Braga Branquinho, Israel Felzenszwalb

litária, e acaba por refletir apenas parcelas específicas da população, diretamente e momentaneamente interessadas (MORAES, 2004). Vale ressaltar que o termo participação pode conter vários significados; advoga-se pois a participação ao menos funcional ou interativa (segundo classificação em PIMBERT; PRETTY, 2000). Segundo esses autores, existem sete estágios de participação popular: 1: passiva - via informações unilaterais e sem possibilidade de reação popular; 2: como extração de informações - as pessoas participam somente doando informações coletada por corpo técnico, não acessando os resultados ou influenciando no processo; 3 : por consulta - a população é ouvida, mas a decisão quanto aos problemas se dá de forma técnica e unilateral; 4: por incentivos materiais - incentivos levam a população a participar com força de trabalho, por exemplo. Normalmente, não envolve aprendizados ou capacitação; 5 Funcional - onde são formados grupos de discussão, primariamente após os estágios iniciais do projeto; 6: interativa - fortalecem-se ou cria-se grupos locais, e estes participam ativamente das tomadas de decisões; 7: automobilização-pessoas tomam iniciativas para mudar sistemas, independentemente das instituições externas. Normalmente se observa a participação popular nos estágios 1 a 4 , que envolvem decisões técnicas unilaterais por parte das instituições envolvidas, visando cumprir somente preceitos legais.

A falta de reconhecimento popular da proposta de gestão da APA pode ser, portanto, um grande entrave ao projeto. Apenas $8,9 \%$ dentre um universo de 606 alunos universitários em Petrópolis declararam conhecer a APA Petrópolis, quando perguntados sobre a existência de unidades de conservação na região (pesquisa em andamento, parte da Tese de Doutoramento do primeiro autor, em curso pelo Programa de Pós Graduação Multidisciplinar em Meio Ambiente da Universidade do Estado do Rio de Janeiro). Esse quadro pode refletir o grau de reconhecimento da unidade e a não legitimação popular da proposta, ao menos nesse recorte social. O próprio contexto de criação da unidade pode ser apontado como fator que auxiliaria a esse não reconhecimento. A política de proteção ao patrimônio cultural local, de caráter privado, forma entidades autônomas do tecido social, valorizando o objeto em sua materialidade a despeito das relações culturais preexistentes e sua diversidade de valores e significados (MAGNANI, 2007), somando-se aí o contexto ambiental.

A descrição da paisagem oriunda do zoneamento ambiental da APA, (publicado em GRAEFF, 2003), foi uma tentativa de se mapear os diferentes usos do território. O resultado, chamado de mapa-síntese, teve como grande benefício compreender minimamente a distribuição dos tipos de terreno, quanto à suscetibilidade a catástrofes ambientais e risco social, e o tipo de ocupação preferível em cada caso. A confecção do mapa-síntese se configura em uma importante ferramenta de gestão, mas ainda deixa a desejar quando omite diversos conflitos socioambientais e suas nuances. Porém, tal tentativa omite diversas realidades socioambientais de agricultores, remanescentes de quilombos, vilas operárias e favelas que não encontram na proposta da APA qualquer espelho de seus anseios ou necessidades. Apesar de aberta e pretensamente sustentável, a proposta da APA esbarra em decisões de ordem técnica que, além de difícil consecução, não refletem as especificidades locais, e a APA passa a ser considerada uma entidade à parte da cidade, reconhecida como objeto físico situado em um distrito da cidade, de papel tão estranho quanto sua localização - A atual sede da APA Petrópolis se encontra do distrito de Itaipava, deslocada do centro historio e político da região e, portanto distante tanto dos conflitos locais quanto do acesso público.

\section{APA Petrópolis versus governos locais}

Inúmeros são os problemas socioambientais que surgem da gestão pelas esferas governamentais locais. Algumas características da gestão local colocam os governos municipais como um dos maiores entraves à conservação da paisagem local, através do descumprimento da legislação em várias esferas. $\mathrm{O}$ zoneamento econômico ligado a interesses privados, a falta de capacidade de execução técnica de projetos e imobilização política são exemplos dos conflitos de gestão (BRAGA, 2001; COUTINHO; ROCCO, 2004) gerando-se uma dificuldade da aplicação de uma democracia participativa nesse nível. Resumidamente, três questões principais podem ser identificadas em termos gerais (SANTOS JUNIOR, 2001): os progra- 
Uma análise contextual do funcionamento efetivo e participação popular em uma unidade de conservação: o caso da área de proteção ambiental de Petrópolis (Rio de Janeiro: Brasil)

Marco Pinheiro Gonçalves, Fátima Teresa Braga Branquinho, Israel Felzenszwalb

mas de reformas institucionais estão desvinculados com os contextos histórico e social, não reconhecendo os atores sociais e políticos locais; a falta de autonomia do poder público frente aos interesses de grupos privados põe em sério risco as prioridades de ação; e a leitura "pouco crítica" sobre as contradições do processo geral de globalização e seus custos sociais. Dentre tais contextos, talvez a primeira questão tenha uma participação especial no caso da APA Petrópolis.

O correto zoneamento urbano demanda pesquisas e fiscalização, competências que inexistem em boa parte das cidades brasileiras, o que incorre em um quadro de ineficiência (inação) e mau uso do solo. A fragilidade do governo municipal relacionada ao poder do capital e a fragilidade técnica enfrentada pelos órgãos municipais em relação à estrutura e execução de projetos urbanísticos e estruturais (BRAGA, 2001) são entrelaçados, resultando no quadro de incapacidade administrativa apresentado por grande parte dos municípios do país. Em outros exemplos, a participação do município gera entraves à gestão de uma APA, por falta de critérios e prioridades, por incapacidade técnica, e pelo não cumprimento de propostas acordadas nas arenas de discussão (caso da APA Cananéia-Iguape-Peruíbe; MORAES, 2004), ou ainda por soluções parciais de caráter técnico e projetos não viabilizados (APA Guaraqueçaba; TEIXEIRA, 2005). No caso de Petrópolis, o baixo grau de ação pública municipal para as questões ambientais, que pode ser exemplificado pela permissividade quanto ao crescimento demográfico sobre áreas de risco, por exemplo (BAPTISTA et al. 2005; BAPTISTA; CALIJURI, 2007) coloca o município no contexto das cidades médias exposto acima. Inúmeros casos de problemas ambientais na coleta e destinação de lixo, a completa ineficiência na fiscalização das ocupações irregulares e a permissividade no estabelecimento de empreendimentos poluidores atestam tal situação. Cotidianamente, observa-se o claro conflito de interesses entre o município e a APA Petrópolis, o que impossibilita as ações em prol da sustentabilidade pretendidas pelo modelo de UC, o que pode ser resumido no quadro I.

Quadro I: resumo dos aspectos da gestão da APA, atores envolvidos e algumas relações entre eles.

\begin{tabular}{|c|c|c|c|}
\hline \multicolumn{2}{|r|}{ Problemas na gestão da APA Petrópolis } & Atores envolvidos & Afetam \\
\hline $\begin{array}{c}\text { Institucionais } \\
\text { Internos }\end{array}$ & $\begin{array}{c}\text { Deficiências de pessoal (numérica e técnica) } \\
\text { Falta de recursos materiais (infraestrutura } \\
\text { para fiscalização, equipamentos de } \\
\text { monitoramento) } \\
\text { Capacitação técnica para questões sociais } \\
\text { locais }\end{array}$ & IBAMA - ICM Bio & $\begin{array}{l}\text { Credibilidade da } \\
\text { Instituição; } \\
\text { legitimação; } \\
\text { promoção da } \\
\text { instituição }\end{array}$ \\
\hline $\begin{array}{l}\text { Institucionais } \\
\text { Locais } \\
\text { (município) }\end{array}$ & $\begin{array}{l}\text { Lentidão e inação fiscalizatórias } \\
\text { Não cumprimento dos compromissos acorda- } \\
\text { dos em plenárias } \\
\text { Não cumprimento da legislação ambiental } \\
\text { Baixa capacidade técnica para idealização e } \\
\text { consecução de projetos }\end{array}$ & $\begin{array}{l}\text { Diferentes órgãos } \\
\text { municipais; parcerias } \\
\text { público-privadas }\end{array}$ & $\begin{array}{l}\text { Correto uso do } \\
\text { solo; } \\
\text { Ocupações } \\
\text { irregulares; } \\
\text { Consecução dos } \\
\text { projetos } \\
\text { conjuntos } \\
\end{array}$ \\
\hline Contextuais & $\begin{array}{c}\text { Baixa participação popular (legitimação) } \\
\text { Distanciamento histórico das questões sociais } \\
\text { da paisagem local } \\
\text { Contexto eminentemente privado dos bens } \\
\text { protegidos } \\
\text { Alta suscetibilidade natural a desastres } \\
\text { ambientais (clima, pluviosidade, geologia) }\end{array}$ & $\begin{array}{c}\text { Representações } \\
\text { populares oficiais ou } \\
\text { não; ONGs; } \\
\text { IBAMA - ICM Bio; } \\
\text { IPHAN }\end{array}$ & $\begin{array}{l}\text { Funcionamento } \\
\text { democrático; } \\
\text { Representação } \\
\text { pública } \\
\text { oficializada; } \\
\text { Muitas zonas de } \\
\text { risco social }\end{array}$ \\
\hline
\end{tabular}


Uma análise contextual do funcionamento efetivo e participação popular em uma unidade de conservação: o caso da área de proteção ambiental de Petrópolis (Rio de Janeiro: Brasil)

Marco Pinheiro Gonçalves, Fátima Teresa Braga Branquinho, Israel Felzenszwalb

\section{CONSIDERAÇÕES FINAIS: AS DIMENSÕES} SOCIOTÉCNICAS E O PAPEL DA EDUCAÇÃO

Foram observados alguns aspectos dos problemas de gestão da APA e da região. Decerto que uma gestão conjunta, que considera a representação popular e a sustentabilidade, pode gerar melhores quadros, sobretudo se houver sintonia entre as esferas municipal e federal. Porém, não é apenas uma análise de excelência em gestão (ARAÚJO; PINTO-COELHO, 2007) que logrará êxito em solucionar os problemas de um sistema tão intricado. As aproximações disciplinares já não dão conta de abraçar o problema: fazem parte dele. Para se abordar os problemas ambientais são necessários novos paradigmas, diferentes daqueles que haviam por trás - inspirando e embasando as ações que os criaram.

Em diversos lugares do mundo situações adversas são evidenciadas em relação aos conflitos entre esforços em conservação ambiental e situações de risco social. Grandes projetos de óticas preservacionistas tradicionalmente excluem as populações locais das arenas de discussão, ou as colocam em papel secundário, como mão-de-obra para os fins de conservação das espécies mais interessantes ou ameaçadas. Notadamente, tais conflitos ocorrem nos países do hemisfério sul, devido principalmente à existência de populações locais isoladas geográfica e culturalmente, porém historicamente relacionadas com extensas paisagens hoje ameaçadas pelo poder globalizante capitalista. Exemplos ocorrem em redes de unidades de conservação em vários países, que concentram esforços para a conservação de animais específicos como o elefante indiano (SAKAR, 2000) o tigre asiático (SHAHABUDDIN; GHATE, 2010), ou dos grandes primatas africanos (SANDBROOK; ROE, 2010). São UCs planejadas distintamente, porém sob a mesma ótica preservacionista, muitas vezes conduzidas por pesquisadores e verbas de países desenvolvidos. Emergem então os problemas em se focar a partir das necessidades ecológicas das espécies, a partir de um arcabouço científico baseado na Biologia da conservação, ignorando as dimensões sociotécnicas e o pano social local. Tal utilitarismo da conservação freia a possibilidade de participação popular efetiva nas UCs, e quando isso se dá, ocorre de forma distorcida e parcial.
As aproximações às comunidades, quando existem, apresentam sérios problemas de falta de efetividade, resultado de falhas na implementação e nas bases conceituais utilizadas. Ambos repousam sobre uma ignorância de aspectos-chaves da política social e antropologia que moldam o manejo tradicional dos ecossistemas, como relatado para UCs do continente asiático relacionadas com a conservação do tigre (SHAHABUDDIN; GHATE, 2010). Mesmo os benefícios do turismo, alegado como o principal fator que alavancaria a situação social geral nas áreas protegidas, se limitariam a apenas alguns segmentos das sociedades afetadas, e seu impacto seria ainda parcamente compreendido (para a Tailândia; SIMS, 2010). Tal inciativa de incentivo do turismo, além de não alcançar o objetivo de redução do risco social, causaria uma ruptura no pano social local e poderia elevar ainda mais a antipatia local acerca dos esforços externos em conservação da paisagem e das espécies (caso dos grandes primatas africanos, SANDBROOK; ROE, 2010).

Tais contextos encontrados no meio internacional encontram eco no Brasil; na maioria dos casos as comunidades não são acionadas à participação, e quando são, cumprem papel acessório e secundário às tomadas de decisão, e seus conhecimentos e seu modo de vida tendem a não participar do conjunto de conhecimentos usado para a gestão das áreas (SERRÃO, 2002; PEDROSO JÚNIOR, 2003). A racionalidade da biologia da conservação como disciplina acadêmica, aliada ao adestramento ambiental (BRÜGGER, 2004) e à ótica científica dominante do século XX é o corpo de conhecimento e práticas que norteia a gestão das unidades de conservação também no Brasil.

Muitos contextos são importantes na existência efetiva de uma UC: os modos de uso mais comuns dos recursos da região, as diferentes intenções de ocupação, os conhecimentos e as divisões culturais históricas, por exemplo. Estes fazem da APA Petrópolis produto e resumo de sua história local, do contexto ambiental e social de seus ocupantes, das características físicas, geográficas, climáticas. Antes de tudo, Petrópolis é fruto de sua história e de suas relações. Estamos nos deparando com um objeto que contém redes de relacionamento - redes sociotécnicas (LATOUR, 1994) - que envolvem desde produtores de hortaliças a produtores de conhecimento técni- 
Uma análise contextual do funcionamento efetivo e participação popular em uma unidade de conservação: o caso da área de proteção ambiental de Petrópolis (Rio de Janeiro: Brasil)

Marco Pinheiro Gonçalves, Fátima Teresa Braga Branquinho, Israel Felzenszwalb

co, científico, tradicional/popular e informacional, compondo uma paisagem transdisciplinar. Rede sociotécnica, na acepção do autor supracitado, faz referência a redes de relacionamento informal que compõem os cenários socioambientais. Tais redes são fruto das interações entre sujeitos e objetos, formando uma dissolução de tais conceitos, em híbridos entre naturezas e culturas, numa rede formada por cientistas, tecnólogos, agricultores e outros, conectando saberes e naturezas, tradição e modernidade. Justificam-se as redes pela urgência em dissolver as visões eminentemente técnico-disciplinares, que historicamente dentro das universidades e repartições públicas engessa os processos de compreensão da paisagem. Em uma paisagem cujas questões transcendem conceitos de gestão, ecologia, engenharia e saúde, compreender as redes será compreender as relações e as urgências.

Senão, como lidar com as relações entre tecnólogos, professores, criadores informais de aves silvestres, as culturas e a ocupação da cidade? Decerto que tudo se conecta, em uma rede de relacionamentos solidária e de interesses onde tudo está ligado, uma rede sociotécnica onde natureza e cultura são indissociáveis. Parece evidente, assim, que um modelo de gestão ambiental que desconhece, massifica ou anula tais interações, na intenção de preservação de um "patrimônio" natural destacado da realidade, está fadado ao fracasso.

No contexto prático, o que se deve fazer, então? Deve-se pretender o fortalecimento do envolvimento dos diversos atores nos sistemas de gestão do espaço. Como esses processos de participação podem ser intensificados? Sabe-se que conselhos gestores, comitês de bacia e agendas 21 - como objetos técnico-científicos construídos a partir dos interesses dos atores que compartilham a rede sociotécnica da crise ambiental - ainda não são completamente reconhecidos e culturalmente freqüentados pelas comunidades (incluindo-se aí a comunidade científica). Normalmente, não se vê a participação oficializada dos setores da população, ficando a participação a cargo de capacidades e vocações individuais (MORAES, 2004). Isso facilita o caráter parcial das discussões, não alcançando os objetivos propostos - ou nenhum objetivo de sustentabilidade - fazendo com que essas arenas, objetos híbridos de natureza e cultura, sejam tomadas apenas como cumprimento de deveres constitucionais, sujeitos e predicados de frases de documentos oficiais, acadêmicos e institucionais. Desse modo, ao contrário da expectativa que geram, tais objetos híbridos têm sublinhada a sua dimensão "objeto" em detrimento da dimensão "sujeito", essa sim, tomada como capaz de agir modificando realidades concretas, agenciando novos interesses, novos atores, produzindo conhecimento socioambiental novo. Da mesma maneira, não se pode destacar as tragédias por escorregamento de encostas e suas vítimas por abordagens simplesmente geológicas ou técnicas; elas são, sem dúvida, fruto da paisagem local, e dos relacionamentos entre a política regional, economia local, eventos climáticos, aspectos históricos e culturais, técnicos e institucionais. As dimensões do problema, decerto, serão melhor visualizadas a partir do que emana a partir da leitura das redes de relacionamento.

Para que uma proposta de UC como esta seja levada a cabo, a legitimação popular é estritamente necessária. Sem ela, não há unidade de conservação. A descrição, o reconhecimento, a valorização das redes sociotécnicas pode gerar interessantes frutos em termos de informação e compreensão do funcionamento de setores da sociedade (BRANQUINHO, 2007).

As redes existentes em APAs passam a ser objeto, portanto, de estudo e pesquisa. Algumas particularidades fazem da APA Petrópolis terreno fértil para o estudo e incentivo dessas redes: são universidades, cursos técnicos e centros de tecnologia onde abundam elos vivos entre os contextos da APA. São universitários que residem nas zonas rurais, professores de colégios públicos que detém conhecimentos tradicionais, estagiários pertencentes a minorias étnicas, operários que estudam o ensino superior à noite. Tais trajetórias em construção são campos para a fertilização de sujeitos ecológicos (CARVALHO, 2005); tal potencial, no entanto, precisa ser explorado.

Uma pesquisa em andamento (parte da Tese de Doutoramento do primeiro autor, como citado anteriormente) permite algumas observações preliminares. Os segmentos universitários - provedores de importantes elos sociotécnicos - elegeram como os principais problemas de Petrópolis o desmatamento desenfreado (18\%), a poluição dos rios (15\%), e construções irregulares (12\%), além da gestão pública (fis- 
Uma análise contextual do funcionamento efetivo e participação popular em uma unidade de conservação: o caso da área de proteção ambiental de Petrópolis (Rio de Janeiro: Brasil)

Marco Pinheiro Gonçalves, Fátima Teresa Braga Branquinho, Israel Felzenszwalb

calização, planejamento, divulgação; 8,9\%). Chama a atenção que 275 alunos dos 606 entrevistados $(45,4 \%)$ não reconhecem nenhuma unidade de conservação da natureza na região. AAPA Petrópolis apresentou baixo grau de reconhecimento, com $8,9 \%$ das respostas. Tais dados permitem observar o questionamento, por parte desses segmentos, da validade das propostas de conservação, assim como da efetividade da divulgação e do funcionamento do aparato público em vários níveis.

É preciso cessar a inatividade histórica das universidades frente às questões socioambientais essa é a provocação que a descrição feita nessa nota objetivava engendrar - e a APA Petrópolis figura, pois, como um laboratório de redes sociotécnicas onde diversos atores, humanos e não-humanos, esperam por serem conhecidos. Petrópolis é hoje conhecida como uma cidade universitária, com vários campi de faculdades públicas e privadas, que atendem a diversos segmentos da sociedade, refletindo o atual quadro do ensino superior nacional. Esse acionamento pode ser realizado na interface entre os centros educacionais, os órgãos da administração pública de caráter executivo e legislativo e as questões ambientais, através de políticas de utilização desses atores no contexto universitário. Monografias, voluntariado, intervenções técnicas, consultorias públicas e cooperativas serão importantes instrumentos de aproximação. Elos solidários devem ser estabelecidos através da formação de intelectuais orgânicos (GRAMSCI, 1985), produtores de conhecimento no âmbito da rede sociotécnica capacitados que são a percorrer diversos caminhos epistemológicos na busca por relações solidárias que têm finalidade da sustentabilidade, na compreensão dos diversos níveis de realidade, no cumprimento das premissas éticas das ações públicas. Caminho longo a ser cumprido, pois demanda das universidades profissionais especiais e vontade política. Como já fora explicitado, uma proposta de unidade de conservação com essa importância e ousadia só pode ser levada a cabo com a efetiva participação dos segmentos da população. Sem ela, não há conservação.

\section{AGRADECIMENTOS:}

Agradecemos à Fundação de Amparo à Pesquisa do estado do Rio de Janeiro - FAPERJ, pela bolsa concedida ao primeiro autor. Este trabalho foi extraído de um conjunto maior de reflexões contido na pesquisa (em desenvolvimento) intitulada "Percepção ambiental de universitários na APA Petrópolis (RJ): análise e proposta de uma aproximação em educação ambiental regionalizada para o Ensino Superior", Tese de Doutoramento do primeiro autor, desenvolvida no âmbito do Programa de Pós Graduação em Meio Ambiente (PPG-MA) da Universidade do Estado do Rio de Janeiro (UERJ). Agradecemos ainda a Anderson Oliveira, pelas contribuições sobre a discussão acerca da geologia petropolitana; e à Giselle Cavalcanti pelo trabalho de revisão.

\section{REFERÊNCIAS:}

ACSELRAD, H. (Org.). Conflito social e meio ambiente no estado do Rio de Janeiro. Rio de Janeiro. Relume Dumará: FASE, 2004.

ARAÚJO, M, A. R. Unidades de Conservação no Brasil: da república à gestão de classe mundial. Belo Horizonte: SEGRAC, 2007.

; R. M. PINTO-COELHO. Utilizando o modelo de excelência em gestão pública para explicar por que as Unidades de Conservação são precariamente geridas no Brasil. In: ARAÚJO, M, A. R. Unidades de Conservação no Brasil: da república à gestão de classe mundial. Belo Horizonte: SEGRAC, 2007. p. 203-214.

ARRUDA, R. 1999. "Populações tradicionais" e a proteção dos recursos naturais em Unidades de Conservação. Ambiente \& Sociedade, v. 5, n. 2, 1999.

BAPTISTA, A. C.; CALIJURI, M. L. Caracterização espaço-temporal por sensoriamento remoto da expansão urbana na APA Petrópolis. In: XIII SIMPÓSIO BRASILEIRO DE SENSORIAMENTO REMOTO Anais..., Florianópolis: INPE 21-26 abr. 2007. p. 5091-5098.

BAPTISTA, A. C.; CALIJURI, M. L.; GONÇALVES, C. E.; SCHAEFER, R.; MARQUES E. A. G. Suscetibilidade das áreas de risco a movimentos de massa 
Uma análise contextual do funcionamento efetivo e participação popular em uma unidade de conservação: o caso da área de proteção ambiental de Petrópolis (Rio de Janeiro: Brasil)

Marco Pinheiro Gonçalves, Fátima Teresa Braga Branquinho, Israel Felzenszwalb

na APA Petrópolis. Natureza \& Desenvolvimento, v. 1, n. 1, p. 51-58, 2005.

BRAGA, R. Política urbana e gestão ambiental: considerações sobre o plano diretor e o zoneamento urbano. In: Carvalho, P. F.; Braga, R (Orgs.): Perspectivas de gestão ambiental em cidades médias. Rio Claro: LPM - UNSEP, 2001, p. 95-109.

BRANQUINHO, F. T. B. O poder das ervas na sabedoria popular e no saber científico. Rio de Janeiro. Mauad X. 2007.

BRASIL, MINISTÉRIO DO MEIO AMBIENTE. SNUC. Lei $\mathrm{n}^{\circ} 9.985$ de 18 de julho de 2000. Institui o Sistema Nacional de Unidades de Conservação e dá outras providências. Brasília, DF, 2000.

BRÜGGER, P. Educação ou adestramento ambiental? 3. ed. Florianópolis: Letras contemporâneas, 2004.

CARVALHO, I. C. M. 2005. A invenção do sujeito ecológico: identidade e subjetividade na formação dos educadores ambientais. In: SATO, M.; CARVALHO. I. C. M. (Orgs.). Educação ambiental: pesquisa e desafios. Porto Alegre: Artmed, 2005.

COLCHESTER, M. Resgatando na natureza: comunidades tradicionais e áreas protegidas. 2000. In: DIEGUES. A. C. (Org.): Etnoconservação: novos rumos para a proteção da natureza nos trópicos. São Paulo: Hucitec, 2000.

COUTINHO, R. L.; R. ROCCO. Apresentação. In: COUTINHO, R. L.; R. ROCCO (Orgs.) O direito ambiental das cidades. Rio de Janeiro, DP\&A. 2004, p.11-16.

COZZOLINO L. F. F.; IRVING, M A. Unidades de Conservação e desenvolvimento local: as APAS do Rio de Janeiro e seus processos de governança local. Disponível em: <http://www.ebape.fgv.br/radma/doc/ POP/POP-032.pdf $>$ Acesso em: 10 nov. 2007.

DIEGUES, A. C. O mito moderno da natureza intocada. 4. ed. São Paulo: Hucitec, 2004.
Etnoconservação da natureza: enfoques alternativos. In: DIEGUES. A. C. (Org.) Etnoconservação: novos rumos para a proteção da natureza nos trópicos. São Paulo: Hucitec, 2000.

GRAEFF, O. APA Petrópolis: zoneamento da área de proteção ambiental. Petrópolis: (Ed.). Autores \& Agentes \& Associados, 2003.

GRAMSCI, A. Os intelectuais e a organização da cultura. Rio de Janeiro, Civilização brasileira, 1985.

GUHA, R. O biólogo autoritário e a arrogância do anti-humanismo. In: DIEGUES. A. C. (Org.): Etnoconservação: novos rumos para a proteção da natureza nos trópicos. São Paulo: Hucitec, 2000.

HOLZER, W. Paisagem, imaginário, identidade: alternativas para o estudo geográfico. In: CORRÊA, R. L. \& ROSENDAHL, Z. (Orgs): Manifestações da cultura no espaço. Rio de Janeiro: EDUERJ, 1999, p. 149-168.

IBAMA-WWF. Efetividade de gestão das Unidades de Conservação Federais do Brasil. Brasília: (Ed.). IBAMA, 2007.

LATOUR, B. Crise. In: Jamais fomos modernos - ensaio de antropologia simétrica. 34. ed. Rio de Janeiro, 1994.

LITTLE, P. Ecologia política como etnografia: um guia teórico e metodológico. Horizontes antropológicos. V. 12, n. 25, 2006.

MAGNANI, J. G. C. Santana do Parnaíba: memória de cotidiano. In: ABREU, R. CHAGAS, M. S.; M. DOS SANTOS (Orgs). Museus, coleções e patrimônios: narrativas polifônicas. Rio de Janeiro: Garamond, 2007. p. 110-123.

MORAES, M. B. R. Área de Proteção Ambiental como Agência de Desenvolvimento Sustentável: APA Cananéia Iguape Peruíbe/SP. São Paulo: Annablume; Fapesp, 2004, 146 p. 
Uma análise contextual do funcionamento efetivo e participação popular em uma unidade de conservação: o caso da área de proteção ambiental de Petrópolis (Rio de Janeiro: Brasil)

Marco Pinheiro Gonçalves, Fátima Teresa Braga Branquinho, Israel Felzenszwalb

OLIVEIRA, A. C. Análise do reuso de áreas industriais suspeitas de contaminação: um estudo de caso de quatro sítios no município de Petrópolis, RJ. 2006. 136 f. Dissertação (Mestrado em Ciências em Saúde Pública na área de Saneamento Ambiental) programa de Saúde Pública da Escola Nacional de Saúde Pública Sérgio Arouca - UFRJ, Rio de Janeiro, 2006.

PEDROSO JÚNIOR, N. Etnoecologia e conservação em áreas naturais protegidas, incorporando o saber local no Parque Nacional do Superagüi. Dissertação de Mestrado, Universidade de São Carlos, São Carlos, 2003. Disponível em: <www.ufmt.br/gpea/pub/ Nelson disserta.pdf>. Acesso em: 11 mai. 2010.

PIMBERT M. P.; PRETTY J. N. Parques, Comunidades e profissionais: Incluindo "Participação" no Manejo de Áreas Protegidas. In: Diegues A. C, (Org.). Etnoconservação: novos rumos para a proteção da natureza nos trópicos. São Paulo: Hucitec; 2000.

SAKAR, S. Restaurando o mundo selvagem. In: DIEGUES. A. C. (Org.): Etnoconservação: novos rumos para a proteção da natureza nos trópicos. São Paulo: Hucitec, 2000.

SANDBROOK, C.; D. ROE. Linking conservation and poverty alleviation: the case of great apes. The poverty and conservation learning group. ARCUS foundation. 2002. Disponível em: $<$ www.povertyandconservation.info/.../20100808-Linking_Ape_Conservation_and_Poverty_Alleviation.pdf $>$. Acesso em: 01 mai. 2011.

SANTOS JUNIOR, O. Q. Democracia e Governo local: dilemas da reforma municipal no Brasil. Rio de janeiro, (Ed.). Revan. 2001.

SANTOS, M. Cap. 5: Paisagem e espaço. Em: Metamorfoses do espaço habitado. São Paulo, HUCITEC, 1994, p. 67-81.

SCHWARTZMAN, S. Florestas cercadas: lições do passado, propostas para o futuro. In: DIEGUES. A. C. (Org.): Etnoconservação: novos rumos para a proteção da natureza nos trópicos. São Paulo: Hucitec, 2000.
SEMADS. Altas das Unidades de Conservação da natureza do Estado do rio de Janeiro. São Paulo, Metalivros, 2001.

SERRÃO, S. M. Para além da mata: Uma discussão sobre o processo de preservação da Reserva da Mata Santa Genebra, Campinas SP. Tese de Doutorado. Universidade Estadual de Campinas, São Paulo, 2002. Disponível em: <http://cutter.unicamp.br/zeus/ auth.php?back=http://cutter.unicamp.br/document/?code $=\mathrm{vtl} 000265201 \& \mathrm{go}=\mathrm{x} \& \operatorname{code}=\mathrm{x} \&$ unit $=\mathrm{x}>$. Acesso em: 07 jul. 2010.

SHAHABUDDIN G.; GHATE, R. Creating Local Constituencies for Tiger Conservation through Community Incentives and Alternative Livelihoods. Washington, D.C.: World Bank, 2010. Disponível em:< http://www.tigersummit.ru/files/Cover_II.pdf $>$. Acesso em: 01 mai. 2011.

SILVA, F. C. T. A história das paisagens. In: CARDOSO, C. F.; VAINFAS, R. (Orgs): Domínios da história: ensaios de teoria e metodologia. Rio de Janeiro: Campus, 1997, p. 203-216.

SIMS, K. R. E. Conservation and development: evidence from Thai protected areas. Journal of Environmental Economics and Management. v. 60 n. 2, 2010. Disponível em: <http://www.sciencedirect.com/science/ article/B6WJ6-506W6J8-1/2/9e21fc041eebf655a74f9296e 5b1bf5c> .Acesso em: 01 mai. 2011.

TEIXEIRA, C. O desenvolvimento sustentável em unidade de conservação: a "naturalização" do social. Revista Brasileira de ciências sociais, v. 20, n. 59, out $/ 2005$.

WILD, R.; MCLEOD, C. (Orgs.). Sacred Natural Sites: Guidelines for Protected Area Managers. Gland, Switzerland: IUCN, 2008. Disponível em:< www. iucn.org/dbtw-wpd/edocs/PAG-016.pdf>. Acesso em: 01 mai. 2011. 